\title{
Curcumin inhibits proliferation and promotes apoptosis of breast cancer cells
}

\author{
SHAN HU ${ }^{1}$, YINGCHUN XU ${ }^{1}$, LIWEI MENG ${ }^{1}$, LIMING HUANG $^{1}$ and HE SUN ${ }^{2}$ \\ ${ }^{1}$ Department of Breast and Thyroid Surgery; ${ }^{2}$ Clinical Laboratory Center, Shaoxing People's Hospital, \\ Shaoxing Hospital of Zhejiang University, Shaoxing, Zhejiang 312000, P.R. China
}

Received December 27, 2017; Accepted March 29, 2018

DOI: $10.3892 /$ etm.2018.6345

\begin{abstract}
Curcumin is a natural compound that appears to be promising for clinical application, as it has been shown in in vitro and in vivo studies to exert antitumor effects by modulating multiple signaling cellular pathways. In the present study, the antitumor effects of curcumin and its mechanism of action were investigated in cultured breast cancer cells. The MTT assay was used to determine the effect of curcumin on breast cancer cell proliferation, flow cytometry was used to detect alterations of the cell cycle, and western blot analysis was used to determine the expression of signaling molecules involved in the cell cycle, proliferation and apoptosis. The results revealed that curcumin significantly inhibited the proliferation of various breast cancer cell lines, such as T47D, MCF7, MDA-MB-231 and MDA-MB-468, with an $\mathrm{IC}_{50}$ at the micromolar level, indicating the potent antitumor activity of curcumin. In-depth study of its mechanism of action revealed that curcumin induced cell cycle arrest at the $\mathrm{G} 2 / \mathrm{M}$ phase and decreased the expression of the CDC25 and CDC2 proteins, while increasing the expression of $\mathrm{P} 21$. In addition, curcumin inhibited the phosphorylation of protein kinase $B$ (Akt)/mammalian target of rapamycin (mTOR), decreased B-cell lymphoma 2 (BCL2) and promoted BCL-2-associated $\mathrm{X}$ protein (BAX) and cleavage of caspase 3, subsequently inducing apoptosis of breast cancer cells. In conclusion, curcumin inhibited the proliferation of breast cancer cells and induced G2/M phase cell cycle arrest and apoptosis, which may be associated with the decrease of CDC25 and CDC2 and increase of $\mathrm{P} 21$ protein levels, as well as inhibition of the phosphorylation of Akt/mTOR and induction of the mitochondrial apoptotic pathway. The findings of the present study may provide a basis for the further study of curcumin in the treatment of breast cancer.
\end{abstract}

Correspondence to: Dr He Sun, Clinical Laboratory Center, Shaoxing People's Hospital, Shaoxing Hospital of Zhejiang University, 568 North Zhongxing Road, Shaoxing, Zhejiang 312000, P.R. China

E-mail:wmcshe@163.com

Key words: curcumin, cell cycle, cell apoptosis, signaling pathway

\section{Introduction}

Breast cancer is the most common type of cancer in women (1) and its development is associated with various factors, such as estrogen level, diet, hereditary susceptibility and obesity (2). These factors contribute to gene mutations, cell cycle abnormalities and loss of the control of epigenetic modification, inducing alterations in a variety of signaling pathways, such as phosphoinositide 3-kinase (PI3K)/protein kinase B (Akt)/mammalian target of rapamycin (mTOR), RAS/RAF/mitogen-activated protein kinase (MAPK), estrogen receptor (ER) and cyclin-dependent kinases (CDKs) $(3,4)$. Although the diagnosis and treatment of breast cancer have markedly improved in recent years, the prognosis of patients with advanced-stage disease remains poor. The incidence of breast cancer is increasing in China, representing a major threat to the health of women. Thus, it is crucial to identify potent new agents for the treatment of breast cancer.

Natural products have attracted the attention of several research scientists for the development of antitumor drugs, due to their proven efficacy and safety. Natural products play an important role in the discovery of lead compounds, and several natural products have been developed and used in clinical practice due to their potent antitumor properties, such as vincristine, camptothecin and paclitaxel. Thus, natural products may represent excellent sources of novel antitumor agents, and a number of them must be further characterized. Curcumin is one of the most important natural compounds, as it was found to possess multiple antitumor properties, and may also sensitize tumor cells to targeted therapy agents and reverse resistance to chemotherapeutic drugs (5).

Several studies reported that curcumin may regulate multiple signaling pathways, including PI3K/AKT, MAPK and nuclear factor (NF)- $\mathrm{\kappa B}(6)$. Curcumin exerts synergistic effects when combined with other chemotherapeutic agents. In breast cancer cell lines, curcumin and paclitaxel exert complementary effects on the alteration of proteins involved in apoptotic and inflammatory pathways (7). Curcumin was shown to induce endothelial growth factor receptor degradation and potentiate the antitumor activity of gefitinib in non-small-cell lung cancer cell lines and xenograft mouse models; intriguingly, it also attenuated gefitinib-induced gastrointestinal adverse effects via altering p38 activation (8). Curcumin was also shown to increase the response of pancreatic cancer cells to gemcitabine through 
attenuating EZH2 and lncRNA PVT1 expression (9). In addition, curcumin was reported to inhibit epithelial-to-mesenchymal transition (EMT) of breast cancer cells $(10,11)$. The focus of this study was the antitumor effect of curcumin on breast cancer cell lines and its underlying mechanism, in order to provide proof of the efficacy of curcumin in the treatment of breast cancer.

\section{Materials and methods}

Cell lines. The breast cancer T47D, MCF7, MDA-MB-415, SK-BR-3, MDA-MB-231, MDA-MB-468 and BT-20 cell lines were purchased from American Type Culture Collection (Manassas, VA, USA). Cells were routinely cultured in complete medium with $10 \%$ fetal bovine serum (Invitrogen; Thermo Fisher Scientific, Inc., Waltham, MA, USA) at $37^{\circ} \mathrm{C}$ in a $5 \% \mathrm{CO}_{2}$ incubator.

Reagents. Curcumin was purchased from Sigma-Aldrich; Merck KGaA (Darmstadt, Germany), diluted in dimethyl sulfoxide (DMSO) at $10 \mathrm{mM}$ and stored at $-20^{\circ} \mathrm{C}$. The primary antibodies against p-Akt, Akt, p-mTOR, mTOR, p-S6, B-cell lymphoma 2 (BCL2), BAX, cleaved caspase 3 and $\beta$-actin were purchased from Cell Signaling Technology, Inc., (Danvers, MA, USA). The antibodies against CDC25, CDC2 and P21, and the secondary antibodies labelled with horseradish peroxidase were purchased from Abcam (Cambridge, MA, USA).

Cell proliferation determination. The breast cancer cells were seeded into 96-well plates at a density of 3,000 cells per well in triplicates. After overnight adherence, the cell lines were treated with various concentrations of curcumin for $72 \mathrm{~h}$. DMSO $(0.1 \%)$ was added to the control wells followed by incubation at $37^{\circ} \mathrm{C}$ for $4 \mathrm{~h}$ after addition of $5 \mathrm{mg} / \mathrm{ml}$ 3-(4,5-dimethyl-2-thiazolyl)-2,5-diphenyl-2-H-tetrazolium bromide (MTT) to each well. Absorbance was measured on VersaMax (Molecular Devices, LLC, Sunnyvale, CA, USA) at $570 \mathrm{~nm}$ after addition of $100 \mu \mathrm{l}$ chromogenic triplex solution (10\% SDS, $5 \%$ isobutyl alcohol and $0.01 \mathrm{M} \mathrm{HCl})$. The $\mathrm{IC}_{50}$ was developed by an inhibition curve and recorded as the mean \pm standard deviation of three independent experiments.

Cell cycle assessment. Cells in the logarithmic growth phase were seeded at a density of $2 \times 10^{5}$ cells/well in a 6 -well plate, incubated at $37^{\circ} \mathrm{C}$ until adherent and treated with 10 or $30 \mu \mathrm{M}$ curcumin for $24 \mathrm{~h}$, while the control cells were treated with $0.1 \%$ DMSO. Cells were harvested into centrifuge tubes and washed with ice-cold phosphate-buffered saline (PBS), then fixed with $700 \mu 1$ ethanol after being detached in PBS at $4^{\circ} \mathrm{C}$ overnight. The cells were collected by centrifugation at $500 \mathrm{x} \mathrm{g}$ for $5 \mathrm{~min}$, then resuspended in $500 \mu \mathrm{l}$ PBS containing $10 \mu \mathrm{g} / \mathrm{ml}$ RNase at $37^{\circ} \mathrm{C}$ for $15 \mathrm{~min}$, followed by staining with $2 \mathrm{mg} / \mathrm{ml}$ propidium iodide (PI) at a final concentration of $10 \mu \mathrm{g} / \mathrm{ml}$ and incubated for $15 \mathrm{~min}$ at $4^{\circ} \mathrm{C}$ in the dark. Analysis was performed on a FACSCalibur analyzer (BD Biosciences, Franklin Lakes, NJ, USA) and the data were analyzed using CellQuest 3.3 software. The tests were performed in three independent experiments.

Cell apoptosis measurement. To determine the effect of curcumin on cell apoptosis, T47D and MCF7 cells in the logarithmic growth phase were seeded at a density of $2 \times 10^{5}$ cells/well in a 6 -well plate and incubated at $37^{\circ} \mathrm{C}$. Then, adherent cells were treated with 10 or $30 \mu \mathrm{M}$ curcumin for $48 \mathrm{~h}$; the control well was treated with $0.1 \%$ DMSO. Cells were detached and washed twice with cooled PBS. Subsequently, the cells were collected and resuspended in cold 1X binding buffer, and Annexin-V and PI (Beyotime Biotechnology, Jiangsu, China) were added into the binding buffer and incubated for $10 \mathrm{~min}$ at room temperature in the dark. Analysis was performed on a FACSCalibur analyzer (BD Biosciences). The tests were performed in three independent experiments.

Western blot analysis. Cells were treated with curcumin for $12 \mathrm{~h}$ at a density of $2 \times 10^{5}$ cells/well in a 6 -well plate. Subsequently, the cells were detached and harvested in RIPA buffer, then kept on ice for $30 \mathrm{~min}$ and centrifuged at $10,000 \mathrm{x} g$ for $15 \mathrm{~min}$. The total protein was quantitated with the BCA protein quantitation reagent kit (Pierce; Thermo Fisher Scientific, Inc.), followed by addition of equal volume of 2X SDS-PAGE loading buffer containing $100 \mathrm{mM}$ Tris- $\mathrm{HCl}$ (pH 6.8), 200 mM DTT, 4\% SDS, 0.1 bromophenol blue and $20 \%$ glycerol, and boiling for $10 \mathrm{~min}$ for denaturation. Equal amounts of total proteins were loaded on the SDS-PAGE gel and electrophoresed in the Tris-glycine electrophoresis buffer [25 mM Tris- $\mathrm{HCl}$ (pH 8.0), $250 \mathrm{mM}$ glycine and 0.1\% SDS] in $100 \mathrm{~V}$ for $1.5 \mathrm{~h}$. The separated proteins were transferred to Hybond-C nitrocellulose membranes in transferring buffer (39 mM glycine, $48 \mathrm{mM}$ Tris and $20 \%$ methanol) for $2 \mathrm{~h}$. The blots were blocked with $5 \%$ non-fat milk in TBST [20 mM Tris- $\mathrm{HCl}$ (pH 7.2-7.4), $150 \mathrm{mM} \mathrm{NaCl}$ and $0.1 \%$ (v/v) Tween-20] for $1 \mathrm{~h}$ at room temperature, incubated with primary antibodies at $4^{\circ} \mathrm{C}$ overnight, and then washed three times with TBST for $10 \mathrm{~min}$, followed by incubation with a horseradish peroxidase-conjugated secondary antibody diluted in blocking buffer for $1 \mathrm{~h}$ and washing three times with TBST for $10 \mathrm{~min}$. The blots were developed with the ECL Plus Western Blotting Detection system (Thermo Fisher Scientific, Inc.). The tests were performed in three independent experiments.

Statistical analysis. Statistical analysis was performed using One-way analysis of variance with the S-N-K method when comparing three groups. $\mathrm{P}<0.05$ was considered to indicate a statistically significant difference. The statistical analysis was performed with SPSS v.13.0 (SPSS, Inc., Chicago, IL, USA).

\section{Results}

Curcumin inhibited the proliferation of breast cancer cells. A variety of breast cancer cell lines, including T47D, MCF7, MDA-MB-415, SK-BR-3, MDA-MB-231, MDA-MB-468 and BT-20, with different ER, progesterone receptor (PR) and human epidermal growth factor receptor-2 (HER2) statuses were selected, and the inhibitory effect of curcumin on these cells was determined after $72 \mathrm{~h}$ of treatment. The results demonstrated that the proliferation of breast cancer cells was dose-dependently inhibited by curcumin (Fig. 1A). The $\mathrm{IC}_{50}$ of curcumin in various cell lines was calculated, and the results revealed different activity of breast cancer cells in response to curcumin. Interestingly, curcumin was more active on $\mathrm{ER}^{+}$ breast cancer cells, such as T47D, MCF7 and MDA-MB-415, 


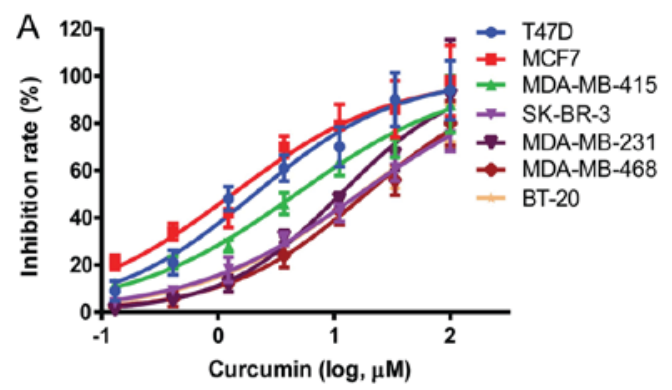

B

\begin{tabular}{|c|c|c|}
\hline Cell lines & IC50 $(\mu \mathrm{M}$, average $\pm \mathbf{s d})$ & ER/PR/HER2 status \\
\hline T47D & $2.07 \pm 0.08$ & ER+PR+HER2- \\
\hline MCF7 & $1.32 \pm 0.06$ & ER+PR+HER2- \\
\hline MDA-MB-415 & $4.69 \pm 0.68$ & ER+PR-HER2- \\
\hline SK-BR-3 & $16.39 \pm 1.25$ & ER-PR-HER2+ \\
\hline MDA-MB-231 & $11.32 \pm 2.13$ & ER-PR-HER2- \\
\hline MDA-MB-468 & $18.61 \pm 3.12$ & ER-PR-HER2- \\
\hline BT-20 & $16.23 \pm 2.16$ & ER-PR-HER2- \\
\hline
\end{tabular}

Figure 1. Inhibitory effect of curcumin on the proliferation of breast cancer cell lines. Breast cancer cell lines were treated with curcumin for $72 \mathrm{~h}$. Cell proliferation was determined by the MTT assay, and $\mathrm{IC}_{50}$ was calculated by four-parameter non-linear regression using GraphPad Prism v.7.0 software (GraphPad Software, Inc., La Jolla, CA, USA). (A) Dose-response curve of curcumin in various breast cancer cell lines. (B) $\mathrm{IC}_{50}$ of curcumin in various breast cancer cell lines. Data represent mean \pm standard deviation from three independent experiments.
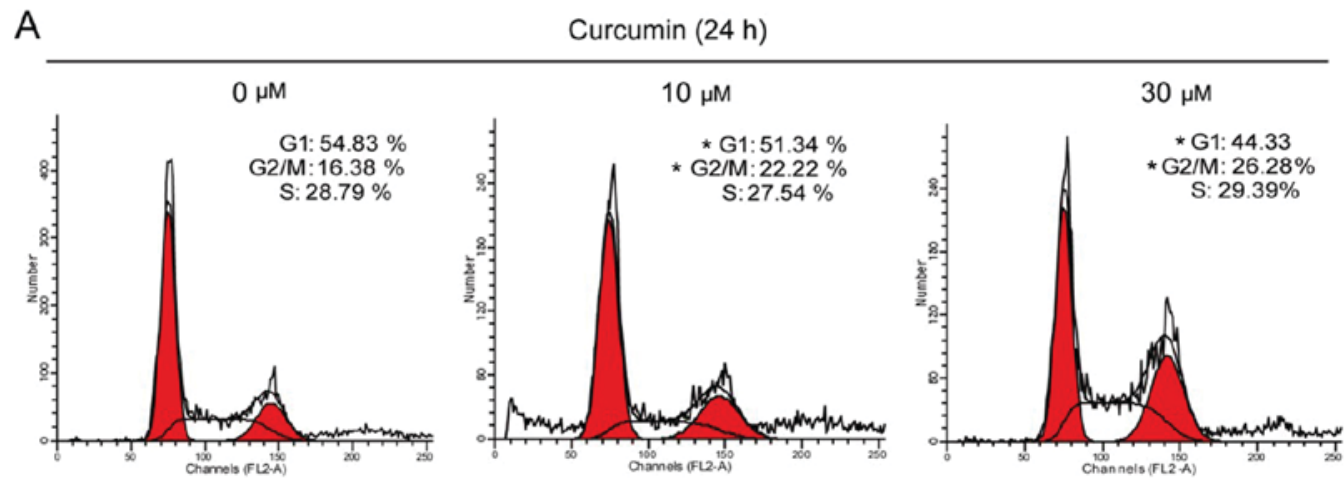

B

Curcumin $(24 \mathrm{~h})$
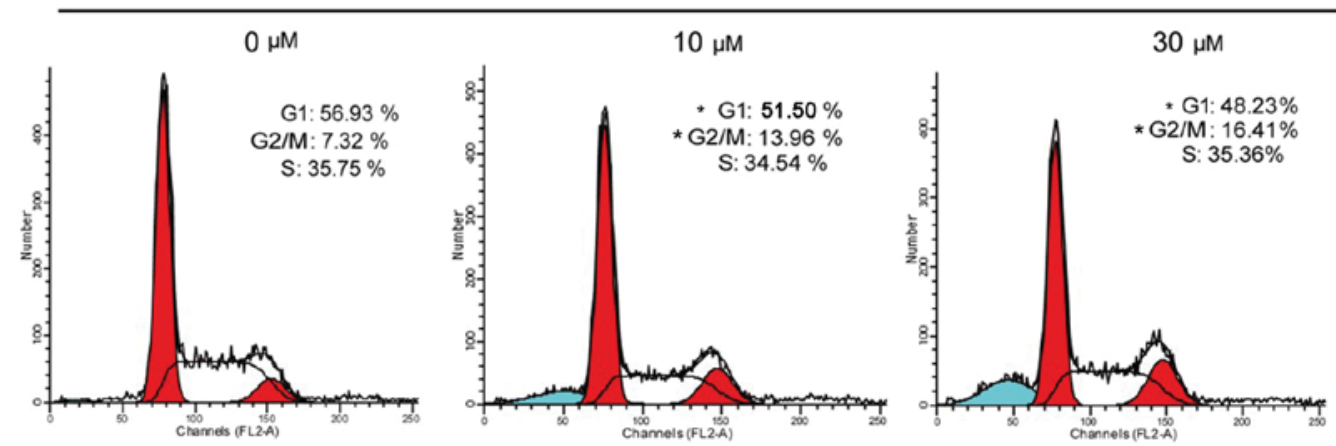

Figure 2. Curcumin induced G2/M arrest in breast cancer cells. (A) T47D cells were treated with 10 or $30 \mu \mathrm{M}$ curcumin for $24 \mathrm{~h}$, and the cell cycle was assessed by propidium iodide (PI) staining using flow cytometry. (B) MCF7 cells were treated with $10 \mathrm{M}$ or $30 \mu \mathrm{M}$ curcumin for $24 \mathrm{~h}$, and the cell cycle was assessed by PI staining using flow cytometry. Data represent mean values from three independent experiments. ${ }^{*} \mathrm{P}<0.05$ compared with the control group by comparing each cell cycle phase.

with an $\mathrm{IC}_{50}$ of $2.07 \pm 0.08,1.32 \pm 0.06$ and $4.69 \pm 0.06 \mu \mathrm{M}$, respectively (Fig. 1B). With regards to the ER-PR-HER2- cells, such as MDA-MB-231, MDA-MD-468 and BT-20 cells, the $\mathrm{IC}_{50}$ was relatively weaker, namely $11.32 \pm 2.13 \mu \mathrm{M}, 18.61 \pm 3.12 \mu \mathrm{M}$ and $16.23 \pm 2.16 \mu \mathrm{M}$, respectively. These results demonstrated that curcumin exerted a more potent effect on $\mathrm{ER}^{+}$breast cancer cells, such as T47D and MCF7; thus, these cells were selected as models for further research on its mechanism of action.

Curcumin induced G2/M cell cycle arrest. To explore the mechanism underlying the antiproliferative action of curcumin, alterations in the cell cycle induced by curcumin were evaluated. T47D and MCF7 cells were treated with 10 or $30 \mu \mathrm{M}$ curcumin for $24 \mathrm{~h}$, and the cell cycle was evaluated by flow cytometry. Our results demonstrated that the cells were arrested in the G2/M phase (Fig. 2). The percentage of T47D cells in the G2/M phase increased from 16.38 to 22.22 and $26.28 \%$ after being treated for $24 \mathrm{~h}$ with 10 and $30 \mu \mathrm{M}$ curcumin, respectively. Similar to T47D cells, the percentage of MCF7 cells in the G2/M phase increased from 7.32 to 13.96 and $16.41 \%$ after being treated for $24 \mathrm{~h}$ with 10 and $30 \mu \mathrm{M}$ curcumin, respectively (Fig. 2B).

Curcumin promoted the apoptosis of breast cancer cells. Next, the effect of curcumin on cell apoptosis was investigated. T47D and MCF7 cells were treated with 10 or $30 \mu \mathrm{M}$ curcumin for $24 \mathrm{~h}$. The results demonstrated that curcumin promoted cell apoptosis. We calculated the early apoptosis (upper right) 
A

Curcumin $(48 \mathrm{~h})$
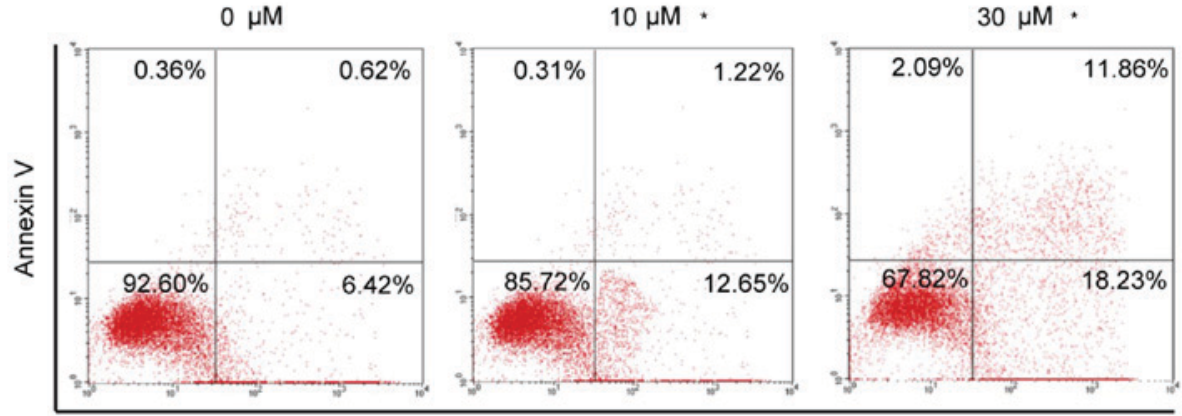

$\mathrm{Pl}$

B Curcumin $(48 \mathrm{~h})$
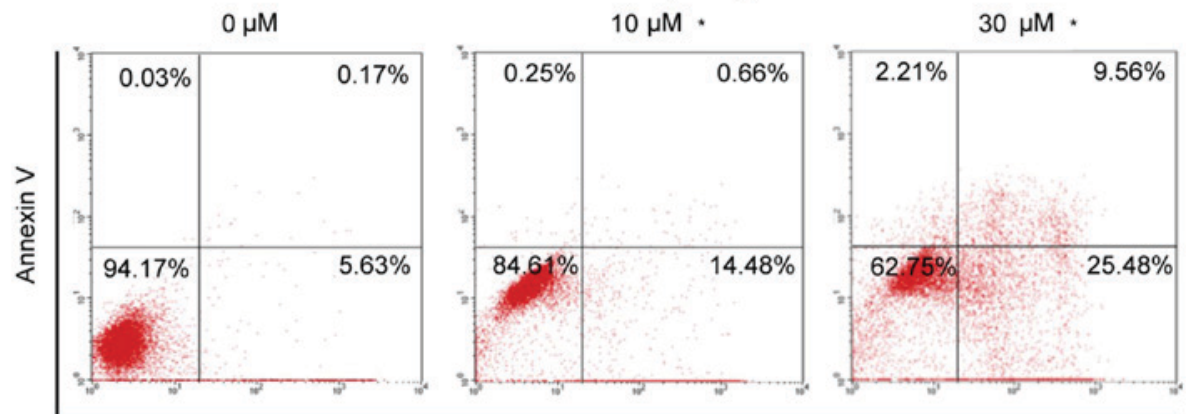

$\mathrm{PI}$

Figure 3. Curcumin induced apoptosis in breast cancer cells. (A) T47D cells were treated with 10 or $30 \mu \mathrm{M}$ curcumin for 48 h, and cell apoptosis was determined by Annexin V and propidium iodide (PI) staining using flow cytometry. (B) MCF7 cells were treated with 10 or $30 \mu \mathrm{M}$ curcumin for 48 h, and cell apoptosis was determined by Annexin V and PI staining using flow cytometry. Data represent mean values from three independent experiments. $\mathrm{P}<0.05$ compared with the control group by comparing early and late apoptosis (upper right and lower right areas, respectively).

and later apoptosis (lower right), and the total apoptotic ratio of T47D cells increased from $7.04 \%$ at baseline to 13.87 and $30.09 \%$ after treatment with 10 and $30 \mu \mathrm{M}$ curcumin, respectively (Fig. 3A). Similarly, in MCT7 cells, the total apoptosis rate increased from $5.8 \%$ at baseline to 15.14 and $35.04 \%$ after treatment with 10 and $30 \mu \mathrm{M}$ curcumin, respectively. In addition, curcumin at $30 \mu \mathrm{M}$ induced some cell debris in T47D and MCF7 cells, as the increased percentage of upper left area. These results revealed that curcumin promoted the apoptosis of breast cancer cells, and MCF7 cells appeared to be more sensitive to curcumin-induced apoptosis compared with T47D cells.

Curcumin regulates the signaling pathways of cell cycle and apoptosis. To achieve a better understanding of how curcumin inhibits the cell cycle and promotes apoptosis, the expression of key signaling molecules involved in these processes was determined by western blotting. The regulatory proteins related to the G2/M phase of the cell cycle, such as CDC25, CDC2 and P21, were detected. CDC25 and CDC2 are accelerators of the G2/M phase, while P21 is an inhibitor. As seen in Fig. 4, the expression of CDC25 and CDC2 proteins was downregulated and that of the P21 protein was markedly upregulated in both T47D and MCF7 cell lines following treatment with curcumin for $12 \mathrm{~h}$. This result indicated that curcumin may affect the cell cycle by regulating the expression of regulatory proteins in the G2/M cell phase. In addition, curcumin was also found to inhibit the phosphorylation of Akt, mTOR and their downstream proteins, which are upstream of the cell cycle proteins, suggesting that curcumin may induce cell cycle arrest through the inhibition of Akt/mTOR signaling.

Curcumin was also found to promote apoptosis of breast cancer cells; thus, the expression of cell apoptotic proteins, such as BCL2, BAX and caspase 3, was also analyzed. BCL2 is an anti-apoptotic protein, while BAX is a pro-apoptotic protein. As seen in Fig. 4B, the BCL2 level was markedly decreased and the BAX level was increased in both T47D and MCF7 cell lines following treatment with curcumin for $12 \mathrm{~h}$ and, correspondingly, the expression of downstream cleaved caspase 3 was increased, suggesting that curcumin may promote the mitochondrial apoptotic pathway.

\section{Discussion}

Curcumin is a well-known natural compound, which has been shown to have pleotropic pharmacological properties, such as antifungal and antitumor properties (12-14). In recent years, the antitumor activity of curcumin has been extensively investigated, and compelling evidence demonstrated that several proteins involved in cancer signaling pathways were regulated by curcumin, such as tumor suppressors P53, P21 and P27, inflammatory regulator $\mathrm{NF}-\kappa \mathrm{B}$, and $\mathrm{Akt} / \mathrm{mTOR}$ in pancreatic and colon cancer (15-17). In the present study, we investigated the antitumor activity of curcumin in breast cancer.

Curcumin was found to be a potent inhibitor on breast cancer cells in vitro, with an $\mathrm{IC}_{50}$ at the micromolar level. Moreover, it acted differently in breast cancer cell lines with a different ER/PR/HER2 status, and favorably inhibited ER ${ }^{+}$ 

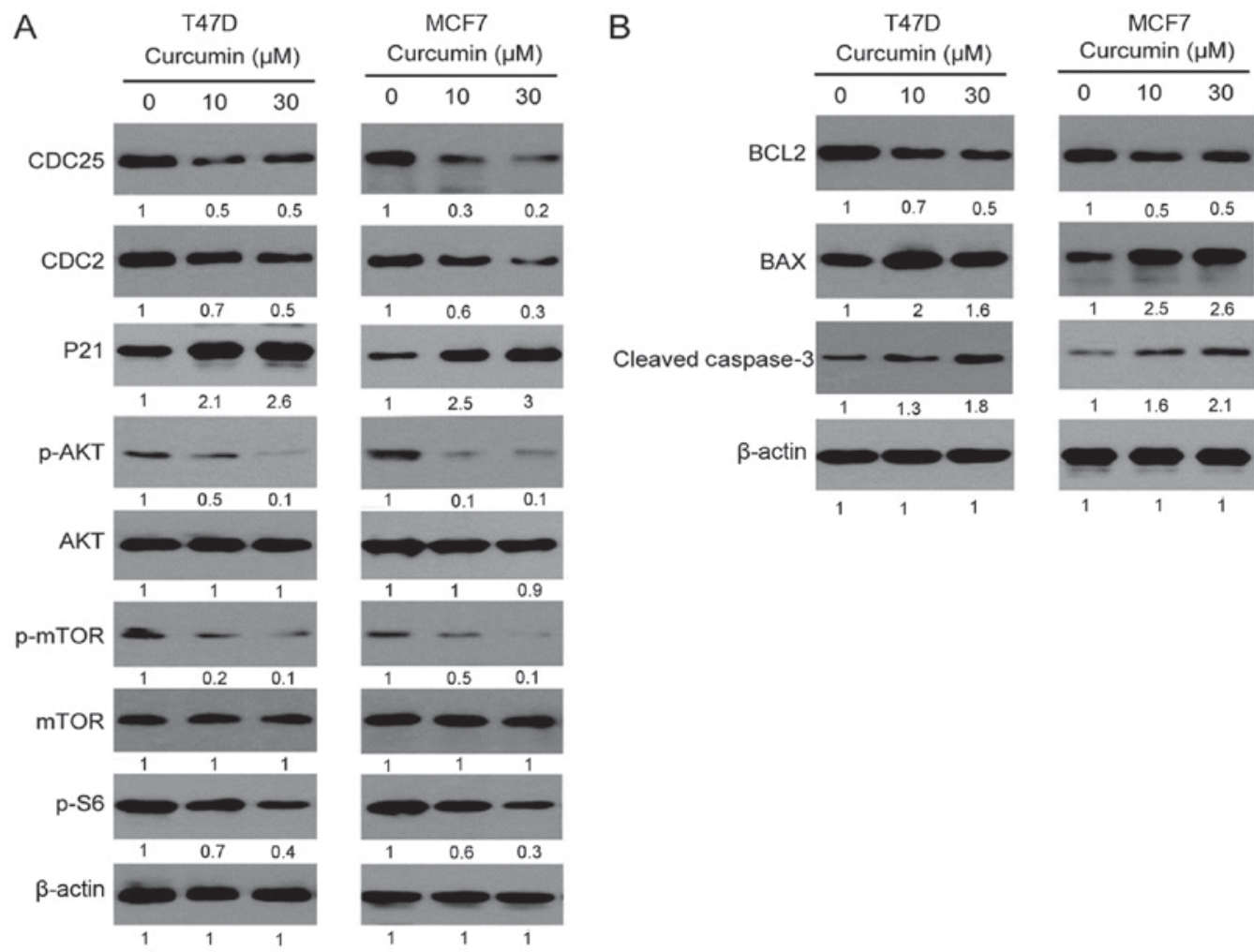

Figure 4. Effects of curcumin on cell cycle, proliferation and apoptosis-related proteins. (A) Curcumin inhibited the expression of CDC25 and CDC2, promoted the expression of P21, and inhibited the phosphorylation of Akt, mTOR and S6 after $12 \mathrm{~h}$ of treatment. (B) Curcumin decreased the expression of the anti-apoptotic protein BCL2, increased the expression of the apoptotic protein BAX, and induced the cleavage of caspase 3 after $12 \mathrm{~h}$ of treatment. The band intensity was analyzed by Image J software, and the expression of proteins is presented as normalized values divided by the control group. Data represent mean values from three independent experiments.

cell lines, such as T47D and MCF7. To further investigate the molecular mechanism underlying the inhibitory effects of curcumin, T47D and MCF7 cells were selected, as they were found to be more sensitive to its actions. The results demonstrated that curcumin caused G2/M cell cycle arrest, which may be one of the key mechanisms underlying the inhibition of cell proliferation in breast cancer. This result is consistent with previous reports of curcumin inducing $\mathrm{G} 2 / \mathrm{M}$ arrest in bladder cancer cells (18). The molecular mechanism underlying this action of curcumin was further explored. CDC25 and CDC2 are important positive regulators and $\mathrm{P} 21$ is a negative regulator of the G2/M phase, and are closely associated with the proliferation and response to chemotherapy of breast cancer cells. We found that curcumin decreased the expression of $\mathrm{CDC} 25$ and $\mathrm{CDC} 2$ and increased the expression of P21. Taken together, our results demonstrated that curcumin blocked the G2/M phase by decreasing the CDC25 and CDC2 levels in addition to increasing the $\mathrm{P} 21$ level.

Breast cancer is a complex disease caused by a variety of factors leading to activation of multiple signaling pathways, including the PI3K/Akt/mTOR, RAF/MEK/ERK and ER pathways. Compelling experimental evidence has demonstrated that targeting the Akt/mTOR pathway is promising for the treatment of breast cancer (19-21). In this study, we found that curcumin exerted an inhibitory effect on Akt/mTOR phosphorylation. The mTOR pathway, in addition to cancer, is also implicated in the pathogenesis of autoimmune $(22,23)$ and infectious diseases $(24-26)$. Thus, we hypothesized that curcumin may also have therapeutic potential in autoimmune and infectious diseases, such as HIV infection. In addition, curcumin may also promote the mitochondrial apoptotic pathway in breast cancer cells, further supporting the therapeutic value of curcumin in breast cancer. Although the preclinical data of curcumin in antitumor treatment are intriguing, several clinical studies with curcumin have yielded disappointing results. Thus, several studies are underway aiming to develop curcumin analogues of higher potency, better bioavailability and longer half-life. For example, allylated monocarbonyl analogues and enone analogues of curcumin were found to promote mitotic arrest and apoptosis by reactive oxygen species-mediated stress $(27,28)$. Novel curcumin analogues exhibited high potency in castration-resistant prostate cancer (29) and nasopharyngeal carcinoma (30). Interestingly, novel curcumin derivatives may exhibit high potency in triple-negative breast cancer cells $(31,32)$; curcumin exhibited lower activity in these cancers cells in the present study, and suggested that optimization of curcumin structure may expand its therapeutic spectrum.

In conclusion, curcumin exerted a potent antitumor effect on breast cancer by inducing cell cycle arrest at the G2/M phase, likely mediated by the decreased expression of CDC25 and CDC2, and the increased expression of P21. Curcumin inhibited the phosphorylation of the Akt/mTOR signaling pathway, decreased the expression of the anti-apoptotic protein BCL2, increased the expression of the apoptotic protein BAX, and induced caspase 3 protein cleavage, leading to cell apoptosis. Thus, these results may 
provide a basis for further study of curcumin in the treatment of breast cancer.

\section{Acknowledgements}

The authors would like to thank the Science and Technology Bureau of Shaoxing for awarding the grant.

\section{Funding}

The present study was supported by a grant from the Science and Technology Bureau of Shaoxing (grant no. 2014B70079).

\section{Availability of data and materials}

The datasets used and/or analyzed during the current study are available from the corresponding author on reasonable request.

\section{Authors' contributions}

SH and HS were responsible for the conception and design of the study. SH, LM and LH collaborated in the development of methodology. SH, LM and HS acquired the data. SH, LM, YX and HS wrote and revised the manuscript.

\section{Ethics approval and consent to participate}

Not applicable.

\section{Patient consent for publication}

Not applicable.

\section{Competing interests}

The authors declare that they have no competing interests.

\section{References}

1. DeSantis CE, Ma J, Goding Sauer A, Newman LA and Jemal A Breast cancer statistics, 2017, racial disparity in mortality by state. CA Cancer J Clin 67: 439-448, 2017.

2. Karimi Z, Jessri M, Houshiar-Rad A, Mirzaei HR and Rashidkhani B: Dietary patterns and breast cancer risk among women. Public Health Nutr 17: 1098-1106, 2014.

3. Hart CD, Migliaccio I, Malorni L, Guarducci C, Biganzoli L and Di Leo A: Challenges in the management of advanced, ER-positive, HER2-negative breast cancer. Nat Rev Clin Oncol 12: 541-552, 2015.

4. Arnedos M, Vicier C, Loi S, Lefebvre C, Michiels S, Bonnefoi $\mathrm{H}$ and Andre F: Precision medicine for metastatic breast cancer-limitations and solutions. Nat Rev Clin Oncol 12 : 693-704, 2015.

5. Zhou QM, Wang XF, Liu XJ, Zhang H, Lu YY, Huang S and Su SB: Curcumin improves MMC-based chemotherapy by simultaneously sensitising cancer cells to MMC and reducing MMC-associated side-effects. Eur J Cancer 47: 2240-2247, 2011.

6. Nagaraju GP, Aliya S, Zafar SF, Basha R, Diaz R and El-Rayes BF: The impact of curcumin on breast cancer. Integr Biol (Camb) 4: 996-1007, 2012.

7. Quispe-Soto ET and Calaf GM: Effect of curcumin and paclitaxel on breast carcinogenesis. Int J Oncol 49: 2569-2577, 2016.

8. Lee JY, Lee YM, Chang GC, Yu SL, Hsieh WY, Chen JJ, Chen HW and Yang PC: Curcumin induces EGFR degradation in lung adenocarcinoma and modulates p38 activation in intestine: The versatile adjuvant for gefitinib therapy. PLoS One 6: e23756, 2011.
9. Yoshida K, Toden S, Ravindranathan P, Han H and Goel A: Curcumin sensitizes pancreatic cancer cells to gemcitabine by attenuating PRC2 subunit EZH2, and the lncRNA PVT1 expression. Carcinogenesis 38: 1036-1046, 2017.

10. Gallardo M and Calaf GM: Curcumin inhibits invasive capabilities through epithelial mesenchymal transition in breast cancer cell lines. Int J Oncol 49: 1019-1027, 2016.

11. Gallardo $\mathrm{M}$ and Calaf GM: Curcumin and epithelial-mesenchymal transition in breast cancer cells transformed by low doses of radiation and estrogen. Int J Oncol 48: 2534-2542, 2016.

12. Khalil OAK, de Faria Oliveir OMM, Vellosa JCR, Quadros AU, Dalposso LM, Karam TK, Mainardes RM and Khalil NM: Curcumin antifungal and antioxidant activities are increased in the presence of ascorbic acid. Food Chem 133: 1001-1005, 2012.

13. Perrone D, Ardito F, Giannatempo G, Dioguardi M, Troiano G, Lo Russo L, DE Lillo A, Laino L and Lo Muzio L: Biological and therapeutic activities, and anticancer properties of curcumin. Exp Ther Med 10: 1615-1623, 2015.

14. El-Houseini ME, El-Agoza IA, Sakr MM and El-Malky GM: NNovel protective role of curcumin and taurine combination against experimental hepatocarcinogenesis. Exp Ther Med 13: 29-36, 2017.

15. Park MJ, Kim EH, Park IC, Lee HC, Woo SH, Lee JY, Hong YJ, Rhee $\mathrm{CH}$, Choi SH, Shim BS, et al: Curcumin inhibits cell cycle progression of immortalized human umbilical vein endothelial (ECV304) cells by up-regulating cyclin-dependent kinase inhibitor, p21WAF1/CIP1, p27KIP1 and p53. Int J Oncol 21: 379-383, 2002.

16. Kunnumakkara AB, Guha S, Krishnan S, Diagaradjane P, Gelovani J and Aggarwal BB: Curcumin potentiates antitumor activity of gemcitabine in an orthotopic model of pancreatic cancer through suppression of proliferation, angiogenesis, and inhibition of nuclear factor-kappaB-regulated gene products. Cancer Res 67: 3853-3861, 2007.

17. Hussain AR, Al-Rasheed M, Manogaran PS, Al-Hussein KA, Platanias LC, Al Kuraya K and Uddin S: Curcumin induces apoptosis via inhibition of PI3'-kinase/AKT pathway in acute T cell leukemias. Apoptosis 11: 245-254, 2006.

18. Park C, Kim GY, Kim GD, Choi BT, Park YM and Choi YH: Induction of $\mathrm{G} 2 / \mathrm{M}$ arrest and inhibition of cyclooxygenase-2 activity by curcumin in human bladder cancer T24 cells. Oncol Rep 15: 1225-1231, 2006.

19. Yang SX, Polley E and Lipkowitz S: New insights on PI3K/AKT pathway alterations and clinical outcomes in breast cancer. Cancer Treat Rev 45: 87-96, 2016.

20. Abraham J: PI3K/AKT/mTOR pathway inhibitors: The ideal combination partners for breast cancer therapies? Expert Rev Anticancer Ther 15: 51-68, 2015.

21. Steelman LS, Martelli AM, Cocco L, Libra M, Nicoletti F, Abrams SL and McCubrey JA: The therapeutic potential of mTOR inhibitors in breast cancer. Br J Clin Pharmacol 82: 1189-1212, 2016.

22. Donia M, Mangano K, Amoroso A, Mazzarino MC, Imbesi R, Castrogiovanni P, Coco M, Meroni P and Nicoletti F: Treatment with rapamycin ameliorates clinical and histological signs of protracted relapsing experimental allergic encephalomyelitis in Dark Agouti rats and induces expansion of peripheral CD4+CD25+Foxp3+regulatory T cells.J Autoimmun 33: 135-140, 2009.

23. Oaks Z, Winans T, Huang N, Banki K and Perl A: Activation of the mechanistic target of rapamycin in SLE: Explosion of evidence in the last five years. Curr Rheumatol Rep 18: 73, 2016.

24. Nicoletti F, Fagone P, Meroni P, McCubrey J and Bendtzen K: mTOR as a multifunctional therapeutic target in HIV infection. Drug Discov Today 16: 715-721, 2011.

25. Donia M, McCubrey JA, Bendtzen K and Nicoletti F: Potential use of rapamycin in HIV infection. Br J Clin Pharmacol 70: 784-793, 2010.

26. Nicoletti F, Lapenta C, Donati S, Spada M, Ranazzi A, Cacopardo B, Mangano K, Belardelli F, Perno C and Aquaro S: Inhibition of human immunodeficiency virus (HIV-1) infection in human peripheral blood leucocytes-SCID reconstituted mice by rapamycin. Clin Exp Immunol 155: 28-34, 2009.

27. Rajamanickam V, Zhu H, Feng C, Chen X, Zheng H, Xu X, Zhang Q, Zou P, He G, Dai X, et al: Novel allylated monocarbonyl analogs of curcumin induce mitotic arrest and apoptosis by reactive oxygen species-mediated endoplasmic reticulum stress and inhibition of STAT3. Oncotarget 8: 101112-101129, 2017. 
28. Deck LM, Hunsaker LA, Vander Jagt TA, Whalen LJ, Royer RE and Vander Jagt DL: Activation of anti-oxidant Nrf2 signaling by enone analogues of curcumin. Eur J Med Chem 143: 854-865, 2018.

29. Chen S, Nimick M, Cridge AG, Hawkins BC and Rosengren RJ: Anticancer potential of novel curcumin analogs towards castrate-resistant prostate cancer. Int J Oncol 52: 579-588, 2018.

30. Pan Y, Liu G, Xiao J, Su B, Zhou F and Wei Y: A novel curcuminoid exhibits enhanced antitumor activity in nasopharyngeal carcinoma. Int J Oncol 48: 2175-2183, 2016.

31. Chang LC, Hsieh MT, Yang JS, Lu CC, Tsai FJ, Tsao JW, Chiu YJ, Kuo SC and Lee KH: Effect of bis(hydroxymethyl) alkanoate curcuminoid derivative MTH-3 on cell cycle arrest, apoptotic and autophagic pathway in triple-negative breast adenocarcinoma MDA-MB-231 cells: An in vitro study. Int J Oncol 52: 67-76, 2018.
32. Taurin S, Nimick M, Larsen L and Rosengren RJ: A novel curcumin derivative increases the cytotoxicity of raloxifene in estrogen receptor-negative breast cancer cell lines. Int J Oncol 48: 385-398, 2016.

(i) () $(9$ This work is licensed under a Creative Commons EY No No Attribution-NonCommercial-NoDerivatives 4.0 International (CC BY-NC-ND 4.0) License. 